\title{
Surface Interaction Model for Great Thickness Masonry
}

\author{
Ariel Sánchez', Gerardo A. González del Solar ${ }^{2,3}$, Pablo E. Martín ${ }^{1,2}$ and \\ Noemi G. Maldonado ${ }^{1,2 *}$
}

${ }^{1}$ Escuela de IV Nivel, Facultad Regional Mendoza, Universidad Tecnológica Nacional, Mendoza, Argentina, ${ }^{2}$ CeReDeTeC, Facultad Regional Mendoza, Universidad Tecnológica Nacional, Mendoza, Argentina, ${ }^{3}$ Consejo Nacional de Investigaciones Científicas y Técnicas, Mendoza, Argentina

\section{OPEN ACCESS}

Edited by:

Vagelis Plevris,

Oslo and Akershus University

College, Norway

Reviewed by:

Panagiotis G. Asteris,

School of Pedagogical and

Technological Education -

Athens, Greece

Constantinos Repapis,

Piraeus University of Applied

Sciences, Greece

*Correspondence:

Noemi G. Maldonado

ngm@frm.utn.edu.ar

Specialty section:

This article was submitted to Earthquake Engineering,

a section of the journal

Frontiers in Built Environment

Received: 08 January 2017

Accepted: 30 March 2017

Published: 19 April 2017

Citation:

Sánchez A, González del Solar GA, Martín PE and Maldonado NG (2017)

Surface Interaction Model for Great

Thickness Masonry.

Front. Built Environ. 3:25.

doi: 10.3389/fbuil.2017.00025
At present, many of the historic masonry structures in the most important seismic zone of Argentina present damages due to the actions to which they have been subjected. Therefore, it is necessary to study the behavior of walls of ceramic masonry of great thickness. This work presents the comparison between the results obtained from the numerical simulation of ceramic masonry walls subjected to compression and shear strength, through the use of interaction surfaces using commercial software ABAQUS, versus the data obtained from physical-mechanical tests performed in 1:1 scale on the laboratory of the CeReDeTeC. Tested walls were made of solid masonry bricks with cement and lime mortar of 26 and $45 \mathrm{~cm}$ thick, respectively. These were compared with the obtained results by the analysis software, considering mortar joints as interaction surfaces, trying to obtain the modeling that represents the behavior of the union of the elements mortar and masonry. The conclusions of the work detail the strengths and weaknesses of this type of masonry modeling and the desirability of developing models that allow to simulate the behavior of great thickness masonry.

Keywords: masonry, heritage, ceramic, great thickness, simulation, interaction surface

\section{INTRODUCTION}

Regulations have been mostly based on the analysis of the response of masonry of standard thickness, with the analysis of the behavior of ceramic masonry walls of great thickness being almost null to date (CIRSOC 501, 2007), as well as its international standardization (Maldonado et al., 2011).

Analysis of the behavior of thick masonry walls under external actions is of essential importance to understand the response that these elements experience and to propose repair methodologies that allow them to recover or even improve their strength.

During the last few years, the structural behavior of masonry-related research has undergone very significant advances. Important studies about the behavior of ceramic masonry during seismic events have been developed. These problems have been numerically modeled, and they have permitted the development of methodologies to verify the behavior of this material; new numerical models that consider structural weaknesses of this material have also been studied and proposed more accurately (Lourenço, 2002; Berto et al., 2004; El-Dakhakhni et al., 2006; Luccioni and Rougier, 2011; Torrisi, 2012).

One of the fundamental concepts regarding the solution of these problems is related to the contact between two or more components. In this way, the relationship between mortar and brick in the joints becomes "the problem to be solved in the model." It is clearly shown that weak element joints are precisely generated in this relationship/interaction. Generic contact is given by two surfaces that interact between them through tangential and normal stress in the interface. This allows the development of resistance mechanisms that occur in general such as friction forces that resist the landslides of the bodies and normal forces that allow the surface to be linked with its adjacent element. 
The utilization of ABAQUS Software (Simulia, 2011) allows the modeling of these interactions through the management of these discontinuous links that enable transmission of forces of one part to another one. These links are intermittent because the forces generated, when the surfaces are in contact, do not apply to them separately. It is important to explain that the modeling and analysis of these contacts allow the most perfect knowledge of the local behavior of structures and then define global features.

This work analyzes the interactions between elements of wide-thickness masonry walls subjected to different types of load (preload upper-shear loads) that simulate the behavior of the wall with seismic load. Behaviors and issues arising from the consideration of the interaction surfaces may reveal this analysis.

Numerous studies are available concerning the behavior of the masonry, as well as the level of macroelements (with homogenization of the model) as micro-modeling. Zucchini and Lourenço (2009) and Page $(1978,1981)$ have worked over the topic, and Lourenço (2002) had studied the situation of the interactions at a general level without modeling in particular, giving a good explanation of the local phenomenon with a watchful view of the physical phenomenon.

Luccioni and Martín (1997) modeled the interfaces according to the models of Lotfi and Shing (1994) and Page (1978) for simple masonry interfaces. This "dilating interfaces" model simulates the failure of horizontal and vertical joints. Alberto et al. (2011) have worked on a reduced damage analysis model for mortar joints. Torrisi (2012) considered similar damage models and interaction models for its proposal of failure in macromodel techniques.

These interfaces simulate the behavior of mortar joints considering tangential and normal behavior on the joint, and it allows a good definition to the directionality behavior, which is important for the phenomenon.

\section{TESTING MATERIALS AND MODELS}

\section{Characterization of the Materials Used in the Masonry Wall Tests \\ Solid Ceramic Brick Masonry}

The solid ceramic brick masonry is made of ceramic brick units joined by an adhesive bridge consisting of a sand mortar with a binder such as the lime that makes up the mortar joints. The description of the failure model is based on the existence of vertical and horizontal weak layers, and the cracks tend to occur in correspondence with these layers. Depending on the thickness of the masonry, joints can be only horizontal or horizontal and vertical, intermittently having more than one in a horizontal plane. There are different types of arrangement of bricks in masonry according to the thickness of the masonry, and the thicknesses vary according to the geometry of local masonry.

In the papers of Page (1981) and Martín (1997), it was shown that the generation of these plans of weakness (joints) permits three main axes of anisotropy; two in the plane of the panel (generated by horizontal and vertical joints) and one perpendicular to this plane, which is due to the interaction of the general model. Certainly, this implies that the location and geometry of the joints generate complex states of stress, which deserve a particular study.

\section{Solid Ceramic Brick}

Brick is the basic element of masonry. The local standard INPRES-CIRSOC 103 (1992) establishes a solid brick as "the element that in any plane parallel to the surface of support has a net area not less than $80 \%$ of the corresponding gross area." These elements have no holes. It is important to mention that the resistance of these elements is mainly dominated by the quality standards under which it is measured. Thus, CIRSOC 501 (2007) calculates the characteristic strength as a percentage of the resistance obtained by a particular number of trials $(n \geq 30)$, and it establishes that the characteristic strength should be achieved by $90 \%$ of the tested parts. This characteristic value is determined by an expression that depends on the average of the values of strength determined by the corresponding tests and the variation coefficient that depends on the dispersion, which have reached during the procedure (limit of dispersion is 0.12).

The variability of strength is important and depends, among other factors, on workmanship. In the development of the model, the characteristics of local materials in the area of El Algarrobal in Mendoza, Argentina, have been used. Table 1 shows the data of the quality of the tested local masonry. Table 2 shows the behavior curve of the tested brick. Young modulus, as tangential modulus, has been obtained.

\section{Mortar Joints}

The bricks are linked together through contact surfaces called mortar joints. They have a similar behavior as that of a concrete with the same dimensions. Conceptually, the mortar is a mixture of cement, lime, sand, and water, components that define the mechanical properties of the material. The water/cement ratio becomes fundamental because it dominates the resistance of the material, its workability, and its general behavior.

It is very important to mention that during the construction of the masonry wall, water absorption of bricks generates a decrease in the available water for hydration of mixture. This effect modifies some characteristics of strength obtained in laboratory, and it does not reflect the real behavior of this material. The material properties that have been quantified and incorporated into the model can be seen in Table 3 .

In addition, the previous constants largely define other intrinsic characteristics of the material (Martín, 1997): compression strength and multiaxial behavior, adherence, modulus of elasticity, multiaxial expansion, ductility, cohesion, plasticity, and strength.

TABLE 1 | Data quality of the tested local masonry brick (ladrillón).

\begin{tabular}{lrrrr}
\hline $\begin{array}{l}\text { Physical and } \\
\text { mechanical } \\
\text { characteristics }\end{array}$ & Year 1985 & Year 1990 & Year 2013 & $\begin{array}{r}\text { Standard } \\
\text { IRAM 1549 }\end{array}$ \\
\hline Length (cm) & $29.87 \pm 0.4$ & $26.93 \pm 0.4$ & $25.99 \pm 0.3$ & $27.00 \pm 1.0$ \\
Thickness (cm) & $8.61 \pm 0.3$ & $7.18 \pm 0.2$ & $6.60 \pm 0.2$ & $5.50 \pm 0.5$ \\
Width (cm) & $18.18 \pm 0.5$ & $17.03 \pm 0.4$ & $16.39 \pm 0.2$ & $13.00 \pm 0.1$ \\
$\begin{array}{l}\text { Flexural strength } \\
\text { (MPa) }\end{array}$ & $2.23 \pm 0.5$ & $3.46 \pm 0.4$ & $3.65 \pm 0.2$ & $2.00 \pm 0.1$ \\
Compressive & $8.25 \pm 0.4$ & $9.85 \pm 1.1$ & $4.01 \pm 0.3$ & $7.50 \pm 0.5$ \\
strength (MPa) & & & &
\end{tabular}


TABLE 2 | Non-linear brick behavior curve $(h=66 \mathrm{~mm})$.

\begin{tabular}{|c|c|c|c|c|c|c|c|c|c|}
\hline \multirow[t]{2}{*}{ Load $\left[\times 10^{3}(\mathrm{~N})\right]$} & \multirow[t]{2}{*}{ Stress (MPa) } & \multicolumn{3}{|c|}{ Deformation (mm) } & \multirow[t]{2}{*}{$\varepsilon(\%)$} & \multirow[t]{2}{*}{$\Delta \varepsilon(\%)$} & \multirow[t]{2}{*}{$\varepsilon_{\text {adjusted }}(\%)$} & \multirow[t]{2}{*}{$\varepsilon_{\mathrm{e}}(\%)$} & \multirow[t]{2}{*}{$\varepsilon_{\mathrm{p}}(\%)$} \\
\hline & & Record & Partial & Accumulated & & & & & \\
\hline 0 & 0 & 5.18 & 0.00 & 0.00 & 0.000 & 0.000 & 0.000 & 0.000 & 0.000 \\
\hline 20 & 0.94 & 7.58 & 2.40 & 2.40 & 0.036 & 0.036 & 0.000 & 0.000 & 0.000 \\
\hline 40 & 1.88 & 7.78 & 0.20 & 2.60 & 0.039 & 0.003 & 0.001 & 0.001 & 0.000 \\
\hline 60 & 2.82 & 8.03 & 0.25 & 2.85 & 0.043 & 0.004 & 0.004 & 0.001 & 0.003 \\
\hline 80 & 3.76 & 8.36 & 0.33 & 3.18 & 0.048 & 0.005 & 0.009 & 0.001 & 0.008 \\
\hline 100 & 4.70 & 8.65 & 0.29 & 3.47 & 0.053 & 0.004 & 0.014 & 0.001 & 0.012 \\
\hline 110 & 5.17 & 8.78 & 0.13 & 3.60 & 0.055 & 0.002 & 0.016 & 0.002 & 0.014 \\
\hline 120 & 5.64 & 9.00 & 0.22 & 3.82 & 0.058 & 0.003 & 0.019 & 0.002 & 0.017 \\
\hline 130 & 6.11 & 9.27 & 0.27 & 4.09 & 0.062 & 0.004 & 0.023 & 0.002 & 0.021 \\
\hline 140 & 6.58 & 9.56 & 0.29 & 4.38 & 0.066 & 0.004 & 0.028 & 0.002 & 0.026 \\
\hline 150 & 7.05 & 10.00 & 0.44 & 4.82 & 0.073 & 0.007 & 0.034 & 0.002 & 0.032 \\
\hline 152 & 7.14 & 10.54 & 0.54 & 5.36 & 0.081 & 0.008 & 0.042 & 0.002 & 0.040 \\
\hline
\end{tabular}

$E_{t g}=3,200 \mathrm{MPa}$.

TABLE 3 | Data for compression curve of mortar.

\begin{tabular}{lccccccc}
\hline $\begin{array}{l}\text { Load } \\
{\left[\times 10^{3}\right.}\end{array}$ & $\begin{array}{c}\text { Stress } \\
(\mathbf{M P a})\end{array}$ & $\begin{array}{c}\boldsymbol{\varepsilon}_{\text {measured }} \\
\mathbf{( \% )}\end{array}$ & $\boldsymbol{\Delta} \boldsymbol{\varepsilon}(\boldsymbol{\%})$ & $\begin{array}{c}\Delta \boldsymbol{\varepsilon}_{\text {adjusted }} \\
\mathbf{( \% )}\end{array}$ & $\begin{array}{c}\boldsymbol{\varepsilon}_{\text {accumulated }} \\
\mathbf{( \% )}\end{array}$ & $\boldsymbol{\varepsilon}_{\mathrm{e}}(\boldsymbol{\%})$ & $\boldsymbol{\varepsilon}_{\mathrm{p}}(\%)$ \\
\hline 0 & & & & & & & \\
5 & 0.00 & 0.000 & 0.0000 & 0.0000 & 0.0000 & 0.00 & 0.00 \\
10 & 1.00 & 1.457 & 1.4569 & 0.0578 & 0.0578 & 0.06 & 0.00 \\
15 & 2.00 & 1.570 & 0.1132 & 0.0578 & 0.1156 & 0.12 & 0.00 \\
20 & 3.00 & 1.678 & 0.1084 & 0.0578 & 0.1735 & 0.17 & 0.00 \\
25 & 4.00 & 1.796 & 0.1179 & 0.0578 & 0.2313 & 0.23 & 0.00 \\
30 & 5.00 & 1.957 & 0.1603 & 0.1603 & 0.3916 & 0.29 & 0.10 \\
31 & 6.00 & 2.263 & 0.3065 & 0.3065 & 0.6980 & 0.35 & 0.35 \\
& 6.20 & 2.525 & 0.2617 & 0.2617 & 0.9597 & 0.38 & 0.58 \\
& 7.50 & 2.970 & 0.4455 & 0.4455 & 1.4053 & 0.43 & 0.97 \\
\hline
\end{tabular}

$E_{\text {calculated }}=1,730 \mathrm{MPa}$.

\section{Description of Used Materials in the Construction of Masonry Model}

Local materials of Mendoza, Argentina, were used for the construction of masonry walls. Solid hand-made clay bricks have been made following the techniques and manual methods of manufacturing. These bricks have an average size of $6.5( \pm 0.13)$ $\mathrm{cm}$ thick, $16.5( \pm 0.17) \mathrm{cm}$ wide, and $26.0( \pm 0.27) \mathrm{cm}$ in length.

Mortar joints were made using Pozzolanic Portland Cement PPC40, hydrated lime, and water from the city of Mendoza. The sand used, locally sourced, was a washed rolled river sand with a density of $2,570 \mathrm{~kg} / \mathrm{m} 3$, water absorption of $2.67 \%$, and fineness modulus of 3.1.

An N-type mortar was designed according to INPRESCIRSOC 103 (1992) with the ratio (cement:lime:sand) 1:1:6.

\section{Description of the Masonry Wall Models Construction Techniques}

The walls were built by local workmanship according to the following methodology:

- The bricks were made wet.

- Mortars and concretes were mixed using electric mixers.

- The supports of walls were built using concrete type H15 (strength required $15 \mathrm{MPa}$ ).
- The masonry was placed with mortar forming the walls in the laboratory of structure on a 1:1 scale.

- The walls were completed with a header that allows uniform application of load in their upper part.

\section{Description of the Types of Models to Be Tested}

Two kinds of models have been developed to be tested. Walls of $30 \mathrm{~cm}$ thickness (M30) and $45 \mathrm{~cm}$ thickness (M45) and $100 \mathrm{~cm}$ wide and $100 \mathrm{~cm}$ high were made to facilitate transport, handling, and placement in the test device and to respect the relationship between dimensions, which allow a behavior similar to that of walls of actual dimensions.

\section{MODEL TESTING}

After the determination of the physical characteristics of the component materials, three walls of $26 \mathrm{~cm}$ thickness and three walls of $45 \mathrm{~cm}$ thickness were tested (Figure 1). The walls of $26 \mathrm{~cm}$ thickness were identified as MMB-08, MMB-09, and MMB-10 and the walls of $45 \mathrm{~cm}$ thickness were identified as MMB-05, MMB-06, and MMB-07 for the tests.

The testing was performed in the structures laboratory of CeReDeTeC. Compression and lateral loads were induced using two hydraulic calibrated jacks. Due to the dimensions and the weight of the specimens in the study, there should be an adaptation to the test. The element is horizontally located on the ground, applying the vertical load through a hydraulic jack on a steel beam, whose function is the distribution of concentrated force on the top header of the test specimen surface. This load is applied at a distance of $10 \mathrm{~cm}$ from the longitudinal edge and centered on the width of the element. This force is balanced, at the same time, by the bottom reaction.

The horizontal load was applied on the top header, and it was balanced by an element located in the lower part of the wall in the area of the foot of the wall. In this way, neither the shear load nor the confinement was directly applied on the specimen, but through the concrete header. The tested setup is shown in 
Figure 2. The walls were subjected to forces with controlled load. For this purpose, a horizontal shear load (Fh) and, simultaneously, a vertical of confinement (Fv) were applied. Both were on the rise, the second in accordance to the first, with a ratio of 1:5. Eight measurement points were placed to determine displacements generated by the applied load in Figure 2. Devices 1 and 2 measured the horizontal displacement in the upper concrete header. Devices 3, 4, 5, and 6 measured the relative vertical displacement between the top and bottom heads. Device 7 measured the horizontal displacement of the specimen base. Finally,
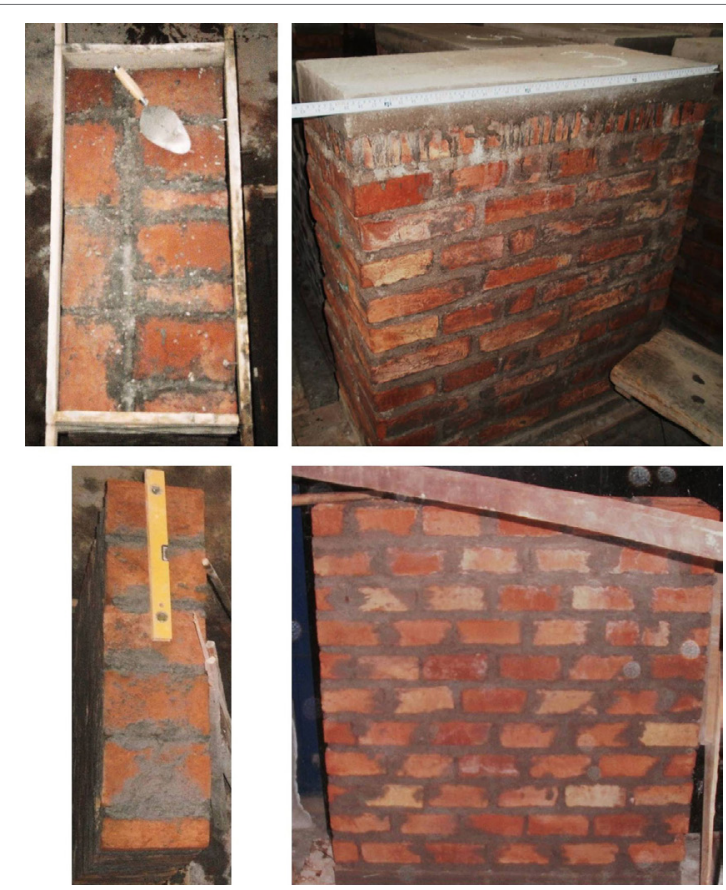

FIGURE 1 | Tested prototype: M45 model (upper) and M30 model (bottom) device 8 measured the vertical displacement on the loading face.

Figure 3 shows the result of testing.

\section{Evolution of Interaction Response (Stress-Strain-Friction Forces)}

The relationship between horizontal displacements and forces applied for the central element of the wall is shown in Figure 4. The displacement increased in the case of a wider wall for the same force applied. This is given in the three tested elements. Figure 5 shows the stress/strain relationship for both analyses.

\section{NUMERICAL SIMULATION OF WALL \\ Description of Equilibrium Interface Equation}

Zucchini and Lourenço (2009) described the behavior of joints and bricks in their interaction. The model described can be divided in one component cell (Figure 6), where the vertical union is presented between two bricks (vertical joint), the horizontal union between two bricks (horizontal joint), and the brick itself. The general deformation of the mechanism can be explained in the following way, before a top horizontal displacement:

- It begins to deform sideways, and joints begin to interact with the masonry, through mechanisms of friction material.

- The vertical joints have lateral displacements since the lower masonry tries to keep to its initial position and the brick on the top moves depending on the load and/or displacement applied.

- The joint $1 \mathrm{~A}$ is under tension since the upper masonry moves laterally in the direction of the applied load, making adjacent masonry move together with a differential deformation on the horizontal axis due to the expansion of the joint driven.

- The joint 1B is compressed, and it allows the movement of the masonry.
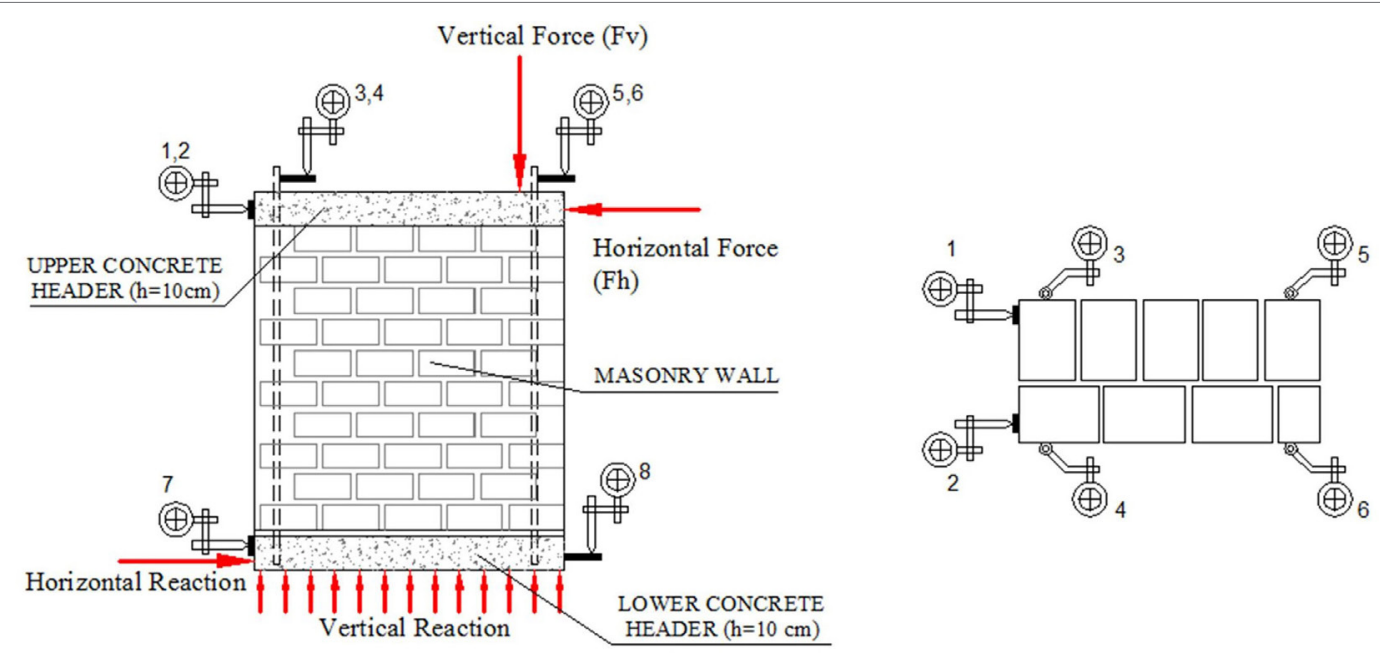

FIGURE 2 | Testing method and measuring points. 

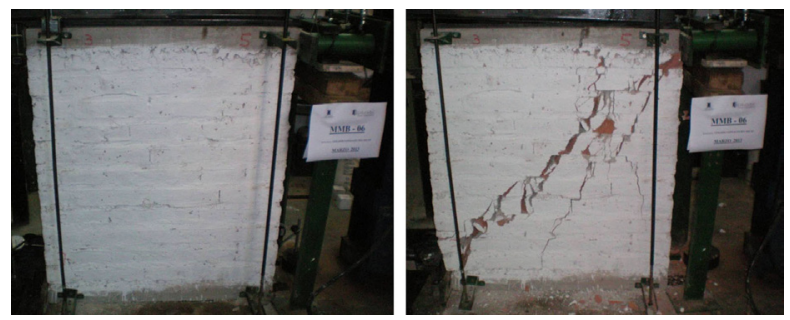

FIGURE 3 | Walls of $45 \mathrm{~cm}$ thickness pre- and post-test.

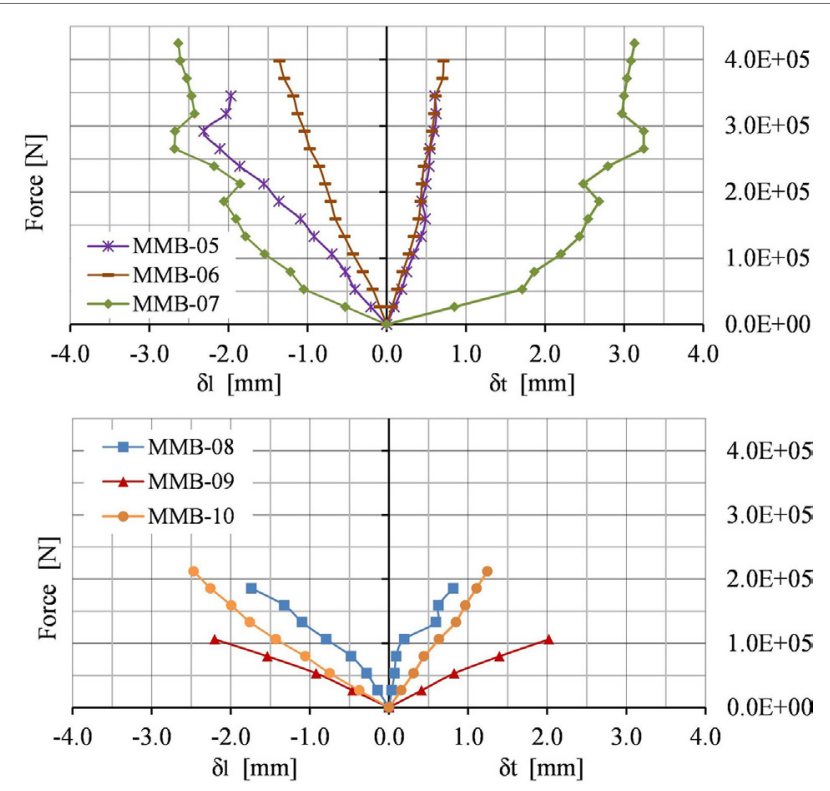

FIGURE 4 | Force-displacement curves measured on principal diagonals, M45 (upper), M30 (bottom).

\section{Numerical Simulation of Interaction Theoretical Analysis of Interaction Model (Friction and Hard Contact)}

Interaction surfaces simulate mortar between masonry joints in the wall model. The relationship between surfaces was called as "surface to surface," which allows managing the surfaces in contact.

This relationship was established through the methodology of two different kinds of surfaces, masters and slaves. This manages the interaction relationship in general, keeping the basic rule that slave surfaces cannot penetrate into the master surfaces. Two models were used to reflect the behavior of the interaction, considering the transverse and longitudinal response of the joint. Thus, the longitudinal behavior was represented under the model of friction, where the transmission of forces occurs through friction of the two surfaces in contact.

The model of the friction phenomena occurs through a coefficient of friction called $\mu$ that responds to the described relationship in Coulomb's law, being proportional to the vertical force applied.
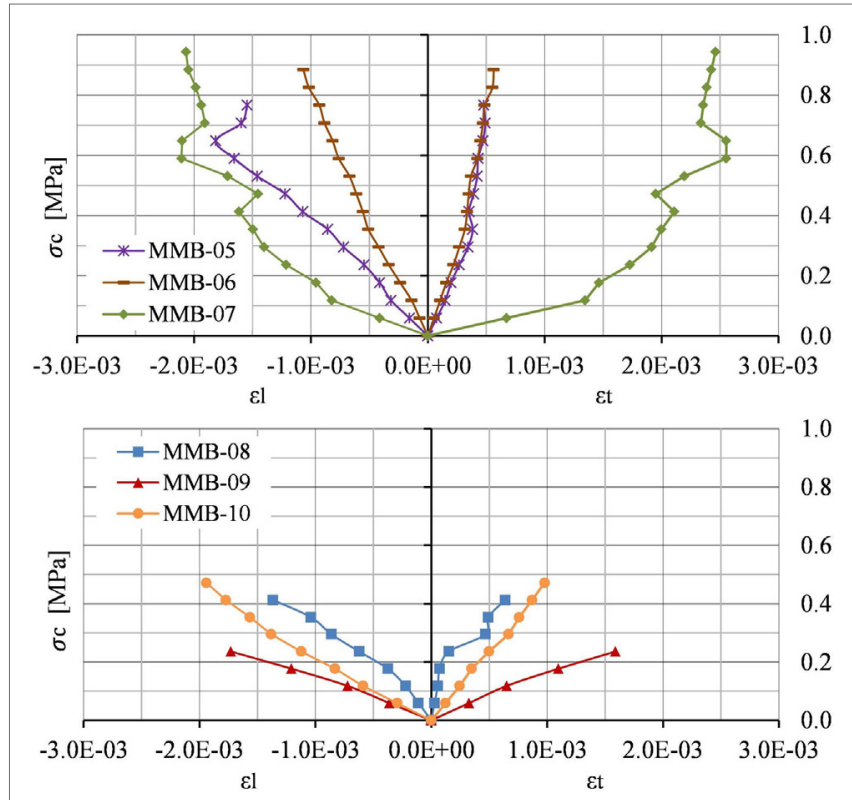

FIGURE 5 | Stress-strain curves measured on principal diagonals, M45 (upper), M30 (bottom).

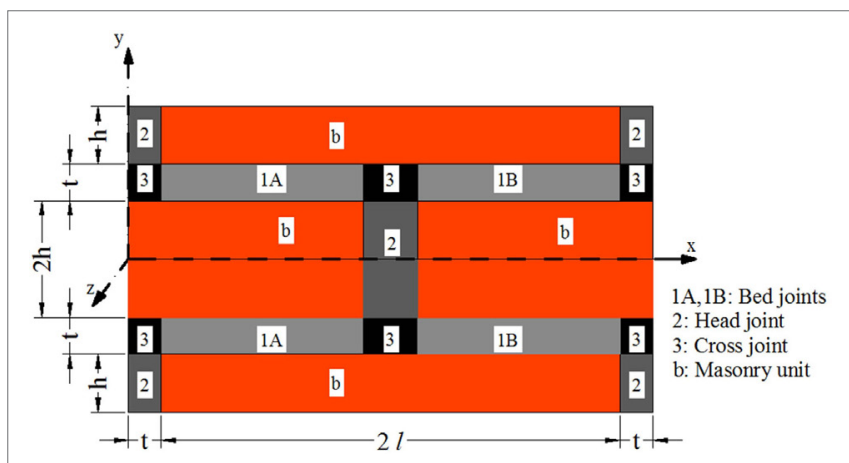

FIGURE 6 | Unit cell.

The condition of normal interaction is defined under the principle that there are no limits in the magnitude of the pressure of contact, which can be transmitted between the surfaces. This implicit concept in the model has allowed defining a normal behavior called hard contact.

\section{Typology and Explanation of Finite Elements Used}

The finite elements considered in the model were the type $3 \mathrm{D}$ stress, with C3D8R internal encoding in the standard order, and linear geometry. This is the standard element of ABAQUS for these problems, with eight nodes of integration $(2 \times 2 \times 2)$, reduced integration, and control of hourglass.

\section{Description of Function of Interaction Model}

The scheme of operation of the interaction model comes from the selection surfaces that are in contact; these surfaces must be defined on the basis of contact with each other, and this defines hard surfaces for deformable elements. As explained in the previous 
paragraph, the definition of surfaces allows interacting between them from the concept of main surface (master) and dependent surface (slave).

Interaction surfaces must be analyzed from the definition of a set of properties according to their behavior. In this case, friction interactions have been used for longitudinal behavior and hard contact-type interactions for normal behaviors. Each of these properties is defined for each type of interaction, whether at the level of horizontal or vertical interactions.

At the level of the interactions of friction, ABAQUS allows the use of several algorithms of response; in this case, Coulomb's friction model has been used, which permits to define a coefficient of friction between materials.

The Coulomb's frictional model allows to consider relative longitudinal displacement to begin when the moving force exceeds a critical value $\tau$ crit $=\mu \cdot p$; where $p=$ pressure of contact between two surfaces. Thus, two contact surfaces begin to slip when shear in the interaction force exceeded this relationship. At this point of "rupture," the process of tension work of adjacent areas begins, yielding or not according to the load to which it is subjected. An increment in the contact pressure implies an increase in the critical stress of displacement, resulting in this case that the material is in longer contact and even fails to slip.

The first step in the iteration is to adjust the relationship between surfaces; this way, parts have been used where the frictional model works well once we have adjusted the resolution of interference between meshes in the first iteration. After this, the model stabilizes and begins to iterate for increases of load. From there, the interaction starts to operate.

The normal behavior of the element defines an interaction of the hard contact type, forcing the model not to have limitations on the pressures of contact to transmit.

\section{Formulation of the Model}

The proposed general model kicks off a non-linear problem that requires the use of a program capable of resolving the large system of equations generated. In the model used, the elements were generated in particular to each type of structural element component of the wall, and each part has been called as:

1. Head: this element simulates a top head that allows the correct distribution of load all over the wall.

2. Horizontal joint: this element is used for horizontal interaction at every level of joints.

3. Vertical joint: this item is used in order to link vertically every brick, together.

4. Brick: it is used to model the masonry element.

5. Half brick: in the border zone, the geometric configuration established the necessity of this element.

6. Bottom head: it simulates a beam of foundation on which the wall stands.

7. Bottom slab: simulates the foundation on which the wall is based.

For each item previously described, different types of materials that were assigned to them (see Description of Used Materials in the Construction of Masonry Model; Tables 1 and 2) were defined. The relationship between each joint and the masonry is generated through the use of an interaction with normal and longitudinal behaviors. In this way, bricks are attached to the joints that are in contact. All these elements were assembled on the masonry wall model.

According to the boundary condition, restrictions were defined on the horizontal axis in the entire frontal-inferior part that corresponds to the simulation of a base slab, on the vertical axis across the base of the model, and in the axis perpendicular to the plane of the wall in the frontal-inferior ridge. In this way, the restrictions by support conditions of the conventional wall were modeled.

Loads to which the model is subjected to be proportional increased up to a maximum $400 \mathrm{kN}$ in vertical load and $265 \mathrm{kN}$ in lateral load.

\section{MODEL'S RESULTS}

In order to achieve a proper distribution of stresses and to minimize errors in the calculation, the discretization of the elements for the masonry was divided in a grid of $2 \mathrm{~cm} \times 2 \mathrm{~cm} \times 2 \mathrm{~cm}$ and joints in $1 \mathrm{~cm} \times 1 \mathrm{~cm} \times 1 \mathrm{~cm}$.

As shown in Figure 7, the minimum stresses are distributed according to different patterns for the $45 \mathrm{~cm}$ and $26 \mathrm{~cm}$ wall sample, respectively. This implies that for thicker walls, central compression strut starts in the head of the wall area and ends in the final third of the wall, not reaching the end or foot of this. For the $26 \mathrm{~cm}$ wall sample, the connecting strut is as expected and has an angle of nearly $45^{\circ}$, starting in the upper vertical meeting and ending at the foot of the element. Figure 7 shows the results considering the mechanical properties of materials tested locally and the obtained values for the wall of $45 \mathrm{~cm}$ thickness, near the 6.16 $\mathrm{MPa}$, with an average of measurement in the area of the central strut $4.5 \mathrm{MPa}$. This is for a pre-compression of $400 \mathrm{kN}$ and a lateral load of $265 \mathrm{kN}$. For the wall $26 \mathrm{~cm}$ thickness, values of stress near the $2.92 \mathrm{MPa}$, with a central strut $2.31 \mathrm{MPa}$, were obtained.

For the maximum values of the principal plastic stress, 3.70E-04 $\mathrm{MPa}$ of maximum tension and average values of $2.18 \mathrm{E}-04 \mathrm{MPa}$ were obtained for the wall of $45 \mathrm{~cm}$ thickness; while for the $26 \mathrm{~cm}$ thick wall, values close to $2.20 \mathrm{E}-04 \mathrm{MPa}$ of maximum tension and average values of 1.08E-04 MPa were obtained.

The displacement at the top of the wall of $45 \mathrm{~cm}$ thickness was close to $6.87 \mathrm{~mm}$, while for the wall of $26 \mathrm{~cm}$ thickness, the displacement at the top was $1.74 \mathrm{~mm}$ (Figure 8).

Tables 4 and $\mathbf{5}$ show the comparable values regarding displacements obtained in the numerical model and experimental analysis for 45- and 26-cm thick walls, respectively.

Figure 9 shows that the estimation of displacements of the model has been quite rough, giving very low errors for the established loads. The last measured displacement is slightly larger, this situation being logical because in the trial the measuring instruments, prior to the break of the model by the existence of the possibility that these could be broken, had to be removed.

\section{DISCUSSION}

At the beginning of the modeling of the walls arises the need to analyze the different types of interaction models available. In this 

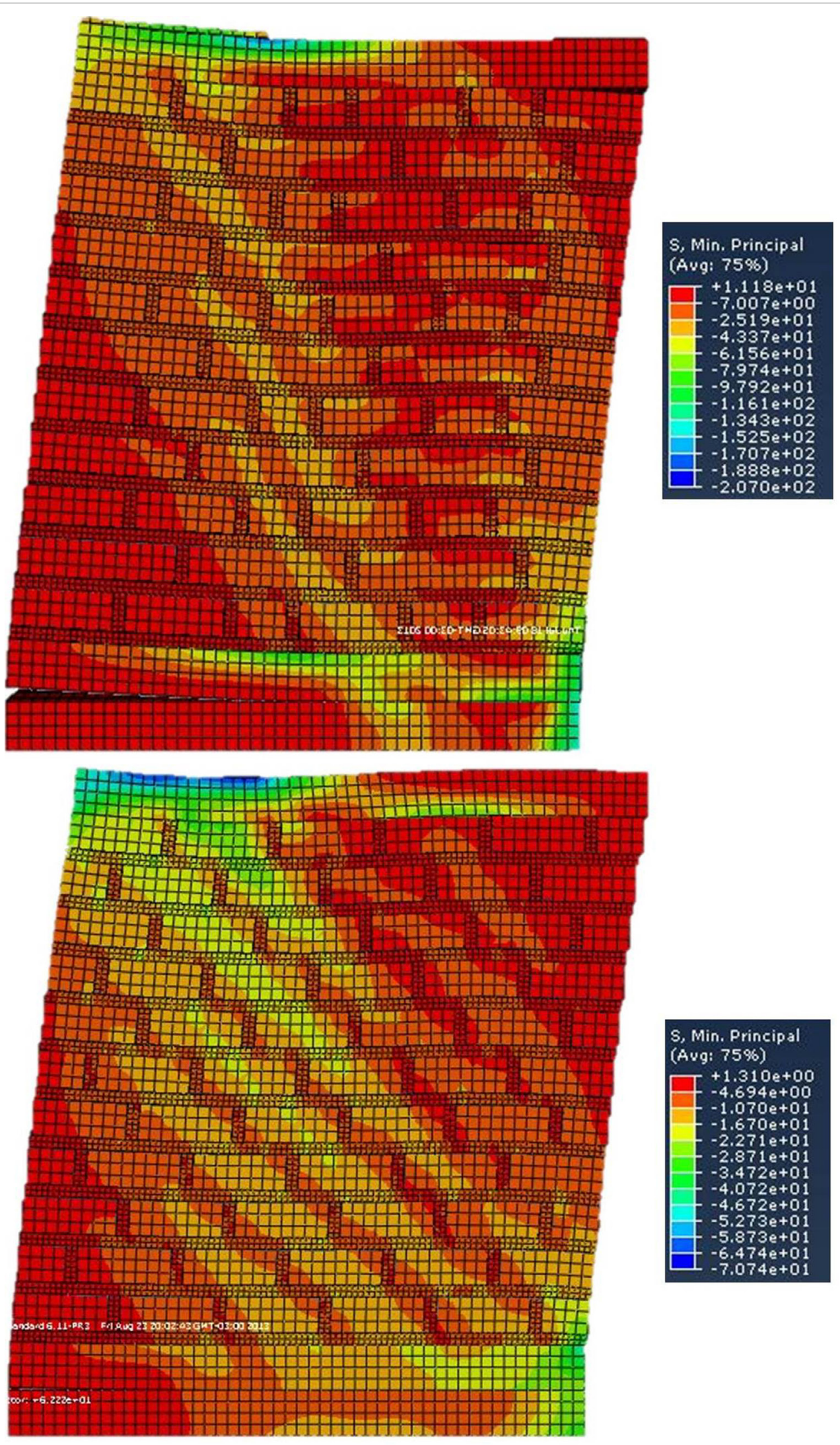

FIGURE 7 | Minimum principal stress: stress $45 \mathrm{~cm}$ model (upper), stress $26 \mathrm{~cm}$ model (bottom). 

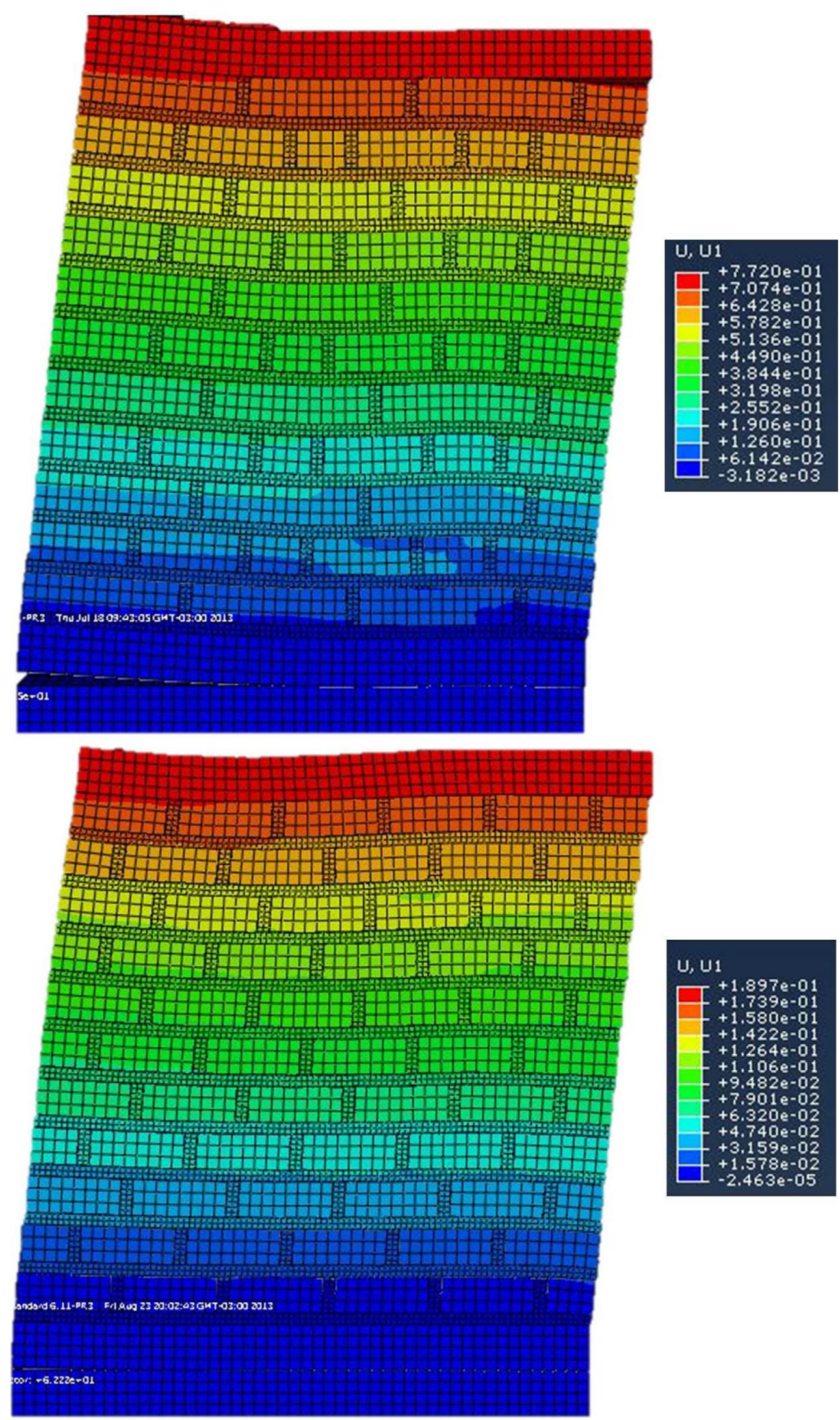

FIGURE 8 | Displacement in U1 direction: M45 model (upper), M30 model (bottom) 
TABLE 4 | Comparison of displacement M45.

\begin{tabular}{|c|c|c|c|c|c|c|}
\hline \multirow[t]{2}{*}{ Loading step } & \multirow[t]{2}{*}{ Vertical load (N) } & \multirow[t]{2}{*}{ Horizontal load (N) } & \multicolumn{4}{|c|}{ Displacement (mm) } \\
\hline & & & MMB-05 & MMB-06 & MMB-07 & ABAQUS model \\
\hline 0 & $0.00 E+00$ & $0.00 E+00$ & 0.00 & 0.00 & 0.00 & 0.00 \\
\hline 1 & $2.21 \mathrm{E}+04$ & $1.47 \mathrm{E}+04$ & 0.12 & 0.13 & 1.19 & 0.00 \\
\hline 2 & $4.41 \mathrm{E}+04$ & $2.94 \mathrm{E}+04$ & 0.24 & 0.26 & 2.37 & 0.32 \\
\hline 3 & $6.62 \mathrm{E}+04$ & $4.41 \mathrm{E}+04$ & 0.29 & 0.46 & 2.66 & 0.51 \\
\hline 4 & $8.83 \mathrm{E}+04$ & $5.88 \mathrm{E}+04$ & 0.39 & 0.65 & 3.66 & 0.69 \\
\hline 5 & 1.10E+05 & 7.35E+04 & 0.46 & 0.83 & 4.25 & 1.03 \\
\hline 6 & $1.32 E+05$ & $8.83 E+04$ & 0.49 & 1.01 & 4.59 & 1.93 \\
\hline 7 & $1.54 \mathrm{E}+05$ & $1.03 E+05$ & 0.58 & 1.09 & 4.97 & 2.60 \\
\hline 8 & $1.77 \mathrm{E}+05$ & $1.18 \mathrm{E}+05$ & 0.63 & 1.17 & 5.05 & 3.36 \\
\hline 9 & 1.99E+05 & $1.32 \mathrm{E}+05$ & 0.75 & 1.22 & 5.28 & 3.92 \\
\hline 10 & $2.21 \mathrm{E}+05$ & $1.47 \mathrm{E}+05$ & 0.76 & 1.43 & 6.16 & 4.49 \\
\hline 11 & $2.43 E+05$ & $1.62 \mathrm{E}+05$ & 0.79 & 1.55 & 6.12 & 4.26 \\
\hline 12 & $2.65 E+05$ & 1.77E+05 & 0.98 & 1.69 & 5.84 & 6.37 \\
\hline 13 & 2.87E+05 & $1.91 \mathrm{E}+05$ & 0.94 & 1.76 & 5.88 & 6.85 \\
\hline 14 & $3.09 E+05$ & $2.06 \mathrm{E}+05$ & & 1.95 & 5.95 & \\
\hline 15 & $3.31 E+05$ & $2.21 \mathrm{E}+05$ & & 2.10 & 6.10 & \\
\hline 16 & $3.53 E+05$ & $2.35 E+05$ & & & 6.20 & \\
\hline
\end{tabular}

TABLE 5 | Comparison of displacement M30.

\begin{tabular}{|c|c|c|c|c|c|c|}
\hline \multirow[t]{2}{*}{ Loading step } & \multirow[t]{2}{*}{ Vertical load (N) } & \multirow[t]{2}{*}{ Horizontal load (N) } & \multicolumn{4}{|c|}{ Displacement (mm) } \\
\hline & & & MMB-08 & ММB-09 & MMB-10 & ABAQUS Model \\
\hline 0 & $0.00 E+00$ & $0.00 E+00$ & 0.00 & 0.00 & 0.00 & 0.00 \\
\hline 1 & $2.21 \mathrm{E}+04$ & $1.47 \mathrm{E}+04$ & 0.11 & 0.63 & 0.35 & 0.02 \\
\hline 2 & $4.41 \mathrm{E}+04$ & $2.94 \mathrm{E}+04$ & 0.21 & 1.26 & 0.69 & 0.03 \\
\hline 3 & $6.62 E+04$ & $4.41 \mathrm{E}+04$ & 0.33 & 2.29 & 1.01 & 0.20 \\
\hline 4 & 8.83E+04 & $5.88 \mathrm{E}+04$ & 0.63 & 4.07 & 1.59 & 0.47 \\
\hline 5 & $1.10 \mathrm{E}+05$ & 7.35E+04 & 0.89 & & 2.04 & 0.88 \\
\hline 6 & $1.32 \mathrm{E}+05$ & $8.83 \mathrm{E}+04$ & 1.09 & & 2.35 & 1.42 \\
\hline 7 & $1.54 \mathrm{E}+05$ & $1.03 E+05$ & 1.55 & & 2.73 & 1.74 \\
\hline 8 & 1.77E+05 & 1.18E+05 & & & 2.97 & \\
\hline
\end{tabular}

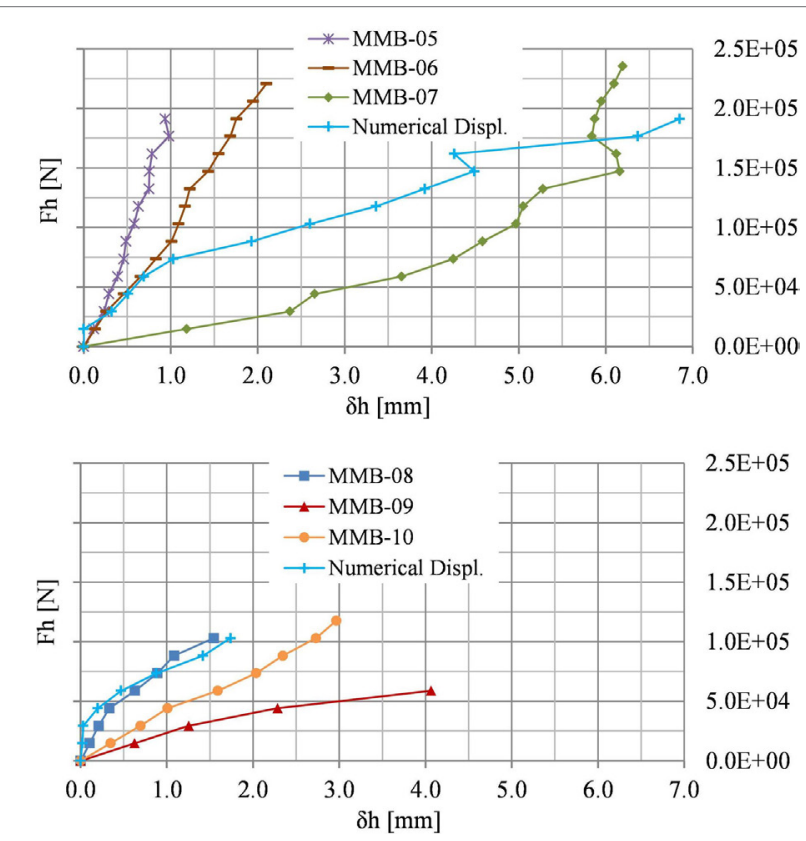

FIGURE 9 | Horizontal force-horizontal displacement curve M45 model (upper), M30 model (bottom). case, the frictional interaction of type joints using brick mortar with a friction coefficient of 0.50 is adopted.

The hard contact-type interaction does not have any limit on the transmitted load by the surface tension. The interaction model used was the ABAQUS standard.

The definition of interactions and contacts must be such that the numerical simulation allows transmitting contact forces, such as the emulated physical problem. In finite element analysis, contact conditions are a particular case of a discontinuous constraint, which allows the transfer of forces from one part of the model to another one. This simulation of the contact is valid since it only applies forces when the two surfaces are in contact.

The results of the tests on local materials showed a very slow speed convergence, more than 7 days of continuous iteration to arrive at a result. This is due to the level of finite element mesh of the components. In addition, the inclusion of interaction elements, which allow gliding between related surfaces, generates new indeterminations that must be solved by the program.

A faster convergence of the model may be associated to curves of non-linear behavior with greater ductility and the non-use of interaction models, even when these give results very representative to the global behavior of the structure. 
The vertical joint, in both cases, creates a more rigid general behavior, in comparison with the case of not taking it into account. The shape of the deformation model varies strongly with this consideration, since different breaking patterns that significantly modify the overall behavior of the element are established.

The wall panel shows the classical central strut where the failure occurs, being more or less tilted depending on the tested wall thickness. In this way, the walls greater than $45 \mathrm{~cm}$ wide, presented in some cases a double strut that can be represented with inclinations greater than $45^{\circ}$ (close to $70^{\circ}$ ) and representing the global failure of the wider wall model. In the $26 \mathrm{~cm}$ wall, the global failure mode is standard with a strut in compression with an inclination of $45^{\circ}$. It is very important to quantify the technical characteristics of each of the boundary to materialize precisely the overall behavior.

\section{CONCLUSION}

The surface interaction model adequately represents the theoretical behavior of the local materials in contact with the typology of the tangential contact.

According to Torrisi (2012), the configuration of the vertical and horizontal joints modifies the stress state of the panel, since the shape of the fault is displaced and the transition points between the sliding fault and the diagonal tension are shifted depending on the resistance characteristics of each.

\section{REFERENCES}

Alberto, A., Antonaci, P., and Valente, S. (2011). Damage analysis of brick-tomortarinterface. Procedia Eng. 10,1151-1156.doi:10.1016/j.proeng.2011.04.191

Berto, L., Saetta, A., Scotta, R., and Vitaliani, R. (2004). Shear behavior of masonry paño: parametric FE analyses. Int. J. Solids Struct. 41, 4383-4405. doi:10.1016/j. ijsolstr.2004.02.046

CIRSOC 501. (2007). Reglamento Argentino de Estructuras de Mampostería. Argentina: INTI.

El-Dakhakhni, W. W., Hamid, A. A., Hakam, Z. H. R., and Elgaaly, M. (2006). "Hazard mitigation and strengthening of unreinforced masonry walls using composites". Compos. Struct.73,458-477.doi:10.1016/j.compstruct.2005.02.017

INPRES-CIRSOC 103. (1992). Norma Argentina de Construcciones Sismorresistentes. Construcciones de Mampostería, Vol. III. Argentina: INTICIRSOC. (in Spanish).

Lotfi, H. R., and Shing, P. B. (1994). Interface model applied to fracture of masonry structures.ASCEJ. Struct.Eng. 120,63-80.doi:10.1061/(ASCE)0733-9445(1994)120:1(63)

Lourenço, P. B. (2002). Computations of historical masonry constructions. Prog. Struct. Eng. Mater. 4, 301-319. doi:10.1002/pse.120

Luccioni, B., and Martín, P. E. (1997). Elastoplastic model for orthotropic materials. Rev Int. Mét. Num. Dis Cálc. Ing. 13, 603-614.

Luccioni, B., and Rougier, V. (2011). In-plane retrofitting of masonry panels with fiber reinforced composite materials. Constr. Build. Mater. 25, 1772-1788. doi:10.1016/j.conbuildmat.2010.11.088

Maldonado, G., Martín, P., and Maldonado, I. (2011). Seismic mitigation of a historic masonry building. Open Constr. Build. Technol. J. 5(Suppl. 1-M3), 61-70. doi:10.2174/1874836801105010061
Consideration of the vertical joint is important to establish clearly the mechanism of failure of the wall, which allows considering locally different fault types.

The computational effort for the analysis of these local phenomena is very important. It is of considerable importance to represent reliably the failure modes in the local phenomenon. This representation allows future outline strategies for a more precise localization in the proper widths (greater than $30 \mathrm{~cm}$ thickness) for repair of walls.

\section{AUTHOR CONTRIBUTIONS}

All authors listed have made substantial, direct, and intellectual contribution to the work and approved it for publication.

\section{ACKNOWLEDGMENTS}

This work is part of the project PICTO RS 255 and PID 25J097 of the Universidad Tecnológica Nacional Facultad Regional Mendoza, National Agency for the Promotion of Science and Technological FONCYT, CONICET, and Government of Mendoza. The authors wish to thank the technical staff of the UTN: Alfredo Cueto, Claudio Dagne, Sergio Acosta, and Prof. Gabriela Castellanos, who have collaborated in the development of the research program.

Martín, P. (1997). Theoric Behaviour of Masonry [Dissertation/Master's thesis]. Tucumán, Argentina: Universidad Nacional de Tucumán.

Page, A. W. (1978). Finite element model for masonry. ASCE J. Struct. Div. 104, 1267-1285.

Page, A. W. (1981). The biaxial compressive strength of brick masonry. Proc. Inst. Civ. Eng. 2, 893-906.

Simulia. (2011). ABAQUS Analysis User's Manual, 6.11. Providence, RI: Dassault Systèmes Simulia Corp.

Torrisi, G. (2012). Design and Analysis of Concrete and Masonry Structures [Dissertation/PhD thesis]. Mendoza, Argentina: Universidad Nacional de Cuyo.

Zucchini, A., and Lourenço, P. B. (2009). A micro-mechanical homogenization model for masonry: application to shear walls. Int. J Solids Struct. 46, 871-886. doi:10.1016/j.ijsolstr.2008.09.034

Conflict of Interest Statement: The authors declare that the research was conducted in the absence of any commercial or financial relationships that could be construed as a potential conflict of interest.

Copyright (c) 2017 Sánchez, González del Solar, Martín and Maldonado. This is an open-access article distributed under the terms of the Creative Commons Attribution License (CC BY). The use, distribution or reproduction in other forums is permitted, provided the original author(s) or licensor are credited and that the original publication in this journal is cited, in accordance with accepted academic practice. No use, distribution or reproduction is permitted which does not comply with these terms. 